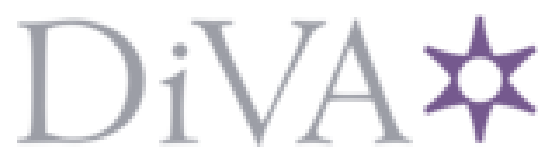

http://www.diva-portal.org

\title{
Postprint
}

This is the accepted version of a paper published in Economic and Industrial Democracy. This paper has been peer-reviewed but does not include the final publisher proof-corrections or journal pagination.

Citation for the original published paper (version of record):

Arnesson, K., Albinsson, G. (2014)

Interaction Patterns within a Steering Group: Power and Outcome.

Economic and Industrial Democracy, 35(2): 325-340

http://dx.doi.org/10.1177/0143831X13481249

Access to the published version may require subscription.

N.B. When citing this work, cite the original published paper.

Permanent link to this version:

http://urn.kb.se/resolve?urn=urn:nbn:se:Inu:diva-45440 


\title{
Interaction Patterns in a Steering Group - Power and Action Outcome
}

\section{Kerstin Arnesson}

Blekinge Institute of Technology, Sweden

\section{Gunilla Albinsson}

Blekinge Institute of Technology, Sweden

\begin{abstract}
The purpose of this article is to study interaction patterns within a steering group. Most large projects include a group of this kind whose task it is to steer towards set goals and provide the required resources. The origin of the research area lies in the observation that steering groups seem to have difficulties in living up to the expectations from project management and project participants, despite structured working methods such as regular meetings, distribution of responsibility and co-operation with different interested parties. By means of interviews and observations we have attempted to capture interaction patterns in a specific steering group. The study is anchored in theories of power with the purpose of supplying theoretical concepts and analytical tools. The most important conclusion is that the interaction patterns that emerged in the steering group rested on two foundations. The first one was that social relations in the steering group created power that was produced and manifested in different ways. The second one was that the exercise of power affected the action outcome, that is, the results of the actions and consequences for future actions. Another conclusion is that the exercising of the assignment presupposes four premises: the steering group member needs to have a positive approach to the project idea and the set goals, to have knowledge of the assignment, to have a position with the authority to make and carry out strategic decisions of the project, and be able to allocate time for active work and participation in meetings.
\end{abstract}

\section{Keywords}

Steering group, interaction patterns, social relations, interplay mechanisms, power perspectives, action outcome 


\section{Introduction}

The purpose of this article is to study interactions patterns within a steering group. The empirical material has been obtained from the Structural Funds project Nurse Gudrun's Fullscale Lab in Blekinge for IT in Nursing and Caring (SGF). This project ran over three years with the aim of demonstrating how digital technology may supplement the existing supply of care and render care processes more effective (Swedish Agency for Economic and Regional Growth, 2008). The purpose is to increase the accessibility for patients in health and medical care by means of information technology. Through changed working methods the patient should be able to receive support and assistance in other ways than through personal meetings without this jeopardizing good health care quality (Landstinget Blekinge, The County Council of Blekinge, 2008).

The interest in the research area has its origin in an on-going evaluation assignment within the SGF (Albinsson \& Arnesson, 2010). Earlier experiences from our own steering group assignments have also led to insights concerning difficulties in living up to the expectations that come from the project managers and the project participants, despite the existence of structured working methods such as regular meetings, distribution of responsibility and cooperation with different interested parties. The question we ask is, therefore, if the understanding of the problems that exist in the steering group may increase through a closer association to the actors and to the meaning and consequences of the actions. We focus our interest on a specific steering group that was active in the project SGF during the years 20082011. The study is anchored in theories of power with the purpose of providing theoretical concepts and analytical tools. Steering groups are, today, not much researched. In addition to the fact that the mode of working in projects has become increasingly common during the last decade, the study is deemed to fill an important gap in current knowledge.

\section{The steering group as part of a project organization}

There are at this point no studies of the interaction pattern of a steering group focusing on power relation between the members. However, several studies describe the interplay between the different actors of the project, and the steering group is then seen as an important part of the organizational structure. A clear distribution of work and coordination between the actors of the project organization are brought forward as decisive for a project to lead to sustainable development.

Research shows, for example, that a functioning steering group along with active ownership, competent project management and committed participants are of decisive importance for a project to reach its set goals (cf. Brulin \& Svensson, 2011; Macheridis, 2009, 2005; Svensson et. al. 2007; Bruzelius \& Skärvad, 2004). In most EU projects, the steering group has the overall responsibility for the goal attainment of the project while smaller projects can be run without a steering group. Another alternative is to combine the overall steering group responsibility with an operative function. Several studies show that for a project to lead to sustainable development, the steering group needs to support the project and work with the implementation to the receiving organizations. Additional factors of significance in this context are the existence of an active ownership, well conducted activities and positive results. The project leader's task is to work with everyday activities and to communicate the project idea with the outside world. (cf. Brulin \& Svensson, 2012; Brulin \& Svensson, 2011; Macheridis, 2009, 2005; Svensson et. al. 2007; Bruzelius and Skärvad, 2004). According to Tonnquist, the task of the steering group is, furthermore, to lay down project directives and the project plan. The members in the steering group need to have the competence to assist and evaluate the project. They often represent the line organization that will receive the project results after the project period (Tonnquist, 2008). Antvik and Sjöholm 
particularly highlight the importance of having the steering group spread information, support the project and the project leader actively, and work for co-operation with the base organization and other interested parties (Antvik \& Sjöholm, 2006).

The description above can, in principle, be transferred to the SGF steering group. This group answered for the following up of the project plan and for ensuring that the result was in line with the project directive. The steering group would, furthermore provide the necessary resources for the realization of the project and together with the project owner make comprehensive decisions, ensure that the project management worked towards the set goals, take responsibility for the spreading of information and actively work with the implementation of the final result to the receiving organizations.

When the project owner appointed members to the first steering group of SGF, the original idea was for the group to meet four times per year and be represented by both resource owners and project receivers. The members were selected among civil servants with the authority to affect the development of activities within respective organization and activities. The members that formed part of the steering group all had long experience of health- and medical care and the majority of the members had earlier worked in projects and/or steering groups. During the first eighteen months of the project, seven steering group meetings were carried out. At the constituent meetings, several members failed to appear, choosing to send substitutes.

During the second operating year of the project, a new steering group was constituted consisting of four members representing both resource owners and project receivers. The strategy was also in this group constellation to have members with positions of authority to affect the development of the respective activities of their organizations. The intention of this new formation was to achieve a more closely united and operative group. Of the four meetings that this group constellation was called to, three were carried out and the group was competent to make decisions in one meeting only. During the third year of SGF, yet one more steering group was formed, consisting of representatives from the County Council of Blekinge, the highest decision-making level. This group convened on four occasions.

\section{Method}

Our intention with the empirical study was to follow a steering group during three years to study factual processes and interaction processes as well as the experiences of the members in the steering group. The study has a qualitative approach where we have alternated between following the work of the steering group nearby and seeking information on a more comprehensive level. This meant that we adopted an active part in relation to the participants and acted in the field of tension between closeness/distance and empirical data/theory. Closeness refers to the understanding of "the actor's point of view" while distance means a physical, social and mental distance, which makes possible reflection and the deepening of knowledge. A central matter for the qualitative approach is also the emphasis of the preunderstanding that the researcher brings into the research process (cf. Dey, 1993; Fielding \& Fielding, 1986; Patton, 2002). In our case, we had earlier experiences of our own steering group engagements which had led to insights into the difficulties of carrying out the steering group assignment.

The qualitative point of departure meant that the methods of participatory/nonparticipatory observation and qualitative interviews were applied. The data material consisted of 14 observations of steering group meetings and 24 qualitatively focused interviews/talks. The data material also included analyses of documents.

The observer method meant that the researchers during a certain time period were in, or in close connection to, a group. This provided an opportunity to establish subject-subject 
relations with the persons that were being observed together with conditions for us to obtain a view from within which otherwise would have been impossible to capture (cf. Cohen et al., 2007).

At the steering group meetings, we took both an active and a passive observer's role. This role can best be described as a continuum from full participation to separation from the situation/interaction that was the object of study. The aspect that we intended to capture was the interaction patterns that could be observed during the steering group meetings. Of interest were the group's social relations, the interaction of the members, what decisions were made, how necessary resources were supplied, and how the group worked towards goals, distributed information and co-operation with other interested parties. Field notes were made, which meant that the contents of the observations were written down in the most complete way possible. The point of departure was that everything that took place was assessed as potentially important (cf. Cohen et al., 2007; Denscombe, 2007; Patton, 2002).

These conditions even led to the writing down of details that seemed unimportant, given that during the on-going observation it was impossible to judge what to select. The observation notes therefore contained descriptions of persons, verbal and non-verbal communication, the actors' ways of acting and also the most complete description of the process as possible. The point of departure was to carry out the observations in the most unbiased way possible and to have the theoretical connection take place first in the phase of analysis.

The observations of the study were combined with qualitative interviews. The purpose of these was to try to capture that which was not possible to observe directly, for example, emotions, thoughts and intentions. The informants' own experiences and understandings thus constituted the focus of the interviews.

The qualitative interviews were characterized by informality and flexibility and the informant's experiences and understanding of working methods, areas of responsibility and interplay were in focus. Methodologically, these interviews corresponded with the semistructured interview which meant that they were largely determined beforehand and the main question areas were written down in an interviewer's guide. (cf. Bryman, 2010; Cohen et al., 2007; Patton, 2002). The qualitative interview was seen as interplay between two individuals with the objective of creating a conversation situation that comprised security and understanding.

The interview persons were 17 people who in their regular work were personnel manager, head of division, project coordinators, professor, care developers, dentist, planning director, investigator, IT managers and nurses. The interviews lasted 1-2 hours and they were recorded and transcribed into text. Seven informants were interviewed more than once.

The analyses of documents constituted a complement to observations and interviews (cf. Cohen et al., 2007; Patton, 2002). The documents that were analyzed were the project application, project directives, and memorandums from steering group meetings and project meetings as well as monthly letters.

Parallel with the realization of observations, qualitative interviews and document analysis, the processing and compilation of the data material was begun. To obtain a coherent picture, data was analyzed by reading the whole of every interview and observation several times. In this first step the purpose was to form an overall view of the meetings and the interviews. In the next step the sections of the text dealing with interaction patterns, interplay, power and action outcomes were marked and after that, in step three, a quotation list was worked out. The fourth step comprised new analyses of the collected data material where patterns, understanding and meanings were sought after.

Observations and interviews often supplemented each other, giving a picture of interaction patterns, power and action outcomes. The analysis resulted in two empirical themes, which 
formed the basis for the account of results. These themes were: "the work of the steering group", and "the interaction patterns of the steering group". In Step five we looked for different interpretations of the results and confirmed that our themes were analyzed from theoretical concepts (cf. Ely, 1997; Svenning, 1993). This theory usage was not a matter of refuting or proving theories validity but should, rather, be seen as a staging of useable theoretical practices. An important condition was to avoid looking on the empirical part as tied to theory, as both meaning and truth can be produced without a specific theory. However, theory dependence is necessary as the researcher can thereby provide alternative interpretations of the reality that is taken for granted and that is construed in every moment (cf. Trondman, 1997). It becomes evident that the empirical material is more complex than theories and analytical concepts have managed to capture.

By means of method triangulation we have, from different angles, tried to capture the experiences and understandings of a specific group. An advantage of multiple qualitative methods is that the researcher covers the problem area in a relatively comprehensive manner. The observations made it possible for us to study the interaction patterns in the steering group and resulted in us not having to rely on the steering group members' own statements. But the observation method included several difficulties. The facts that the researcher can never discern more than fragments of a situation and that research data are always smaller to their extent than the research situation are imperative facts that we have come to learn at the time of the observations. During the interviews, one of the problems for the interviewer was to stay focused on the interviewed person's statements. The interviewed persons would often speak of matters that were irrelevant to the study. As a researcher it was then easy to lose concentration and start reflecting on one's own experiences or thinking about the formulation of the next question.

\section{Results}

\section{The work of the steering group}

The project owner's strategy at the selection of steering group members was supported by all informants. A high management level with the authority to make independent decisions was seen as a condition for the project to have an impact in the activities of the organization. The observations that were carried out through the first months of the project showed, however, that the composition of the group turned out differently than the one determined by the project owner (Observations 1, 2, 3). The following quotes illustrate this:

\footnotetext{
The thing was, I guess, that nobody wanted to take on this assignment. Then I had to take it at short notice (Interview 9).

I did not get this assignment because I was particularly suited for it but because nobody else had time for it. There had to be a representative from our administration (Interview 11).

I got the assignment because I happened to be present when the matter was discussed. The administration manager was supposed to take it, but she did not have time. So then I had to replace her (Interview 15).
}

According to several members in the steering group, it was unclear how they had been selected and which tasks they had. The assignment was, for example, considered to be included in the position or it had been assigned according to an informal "priority list". To be selected as a substitute meant, in several cases, not having any real authority to have an 
influence, with lack of motivation as a consequence. But there were also people who felt passed over, considering that they should have had a given place in the group:

\begin{abstract}
I had to force my way in. My participation should have been a natural thing from the beginning because the project really affects my work. The project would have benefited from me being a participant earlier, but I don't think that they wanted me there because there was a risk that I would place demands on the project (Interview 4).
\end{abstract}

The quote can be interpreted as this steering group member arguing in favor of her/his own interests. This also became evident when this person pursued a matter based on priorities from the activities of her/his own organization resulting in delayed activities in the project (Observation 10).

According to the informants of the study, the primary task of the steering group was to make decisions for the project to develop in accordance with the project directive, but also to give support to the project leader and provide information about the project in the activities of the members' own organizations. To obtain a well-founded basis for decision-making, every steering group member had the responsibility to keep informed about the project and the outside world. Several members were of the opinion that this assignment was "floating and vague" and that there were unclear expectations concerning what had to be done resulting in a low sense of responsibility. The following three quotes illustrate this:

\begin{abstract}
It probably says in some papers what we should do, but I find the assignment floating and vague. We are supposed, I guess, to direct together with the project leader (Interview 14).

During the meetings I keep thinking about what is expected of me. I can't figure it out. /.../ I feel as if I have not contributed anything concrete /.../ I read everything that has been written about the project, for example, the project plan, project directives and notes from the meetings to understand the project and keep updated. Then I don't really know what to do with that (Interview 11).
\end{abstract}

The members don't know their tasks and they don't know who they represent. They don't know that they need to both find information and give information. If they get an assignment to do for next meeting, they don't care. They come to the meeting without having done anything (Interview 10).

To be able to grow into the work, clearer information about the assignment was asked for. In our interviews, the opinion that the work of the steering group should be more specified came back often, and somebody compared it to how the work in a board of directors is carried out and distributed between board members and the managing director.

Several members of the steering group also emphasized the importance of the feeling of participation, viewing this as a basis for anchoring the project with decision-makers on higher levels and in the activities of their respective organizations. To be actively able to work with the assignment, the suggestion was to increase the number of meetings from four to a minimum of six per year and to allocate time for the assignment within the framework of the regular position. Certain insecurity existed, however, concerning how information about the project would be disseminated. The difficulty of implementing the project could, in several cases, be explained by the fact that some of the group members had a position in the hierarchy of the county council which meant that they lacked authority. These steering members had to consult in turn with their own managers when decisions concerning SGF were to be made.

In an early phase, the project leader called attention to the fact that she needed increased support from the steering group. Forward-looking decisions were called for as were 
opportunities to carry out the different tests of the projects in the organizations of the respective steering group member.

According to our informants, the steering group meetings were characterized by working methods not properly thought out and by ignorance about the project. As the group was seldom complete, the project owner spent a large part of the meeting giving general information, descriptions of the present situation and feedback (Observations 3, 4, 5, 6, 7, 8, $9,10)$. This discontinuity led to the delay of important project decisions or to these decisions not being made at all. At the end of the project period, the working methods were, however, drawn tighter and a clear allocation of responsibility with demands on reporting back was set up. This new way of working led to greater efficiency and several project goals were attained during this period (Observation 12, 13, 14).

The assignment of the steering group was to take responsibility for following up the project plan and making sure that the result was in line with the project directive and the set goals. When the interview persons reflected upon this, the opinions varied from diffuse ideas of the project goals, seeing them as "muddled" and "unclear," to general ideas of the project being "good" and "stretchable":

\footnotetext{
The steering group should steer towards set goals. The goals are so well formulated that you can do almost anything or, rather, many things are embraced by each goal. If you get stuck you can do something else (Interview 2).

It's not easy to move towards the set goals when the project never starts $/ \ldots /$ Because they never get going with any activities. I think that the project should be interrupted; it lives its own life, it does not follow the project directive and it manages the finances in an irresponsible manner (Interview 6).
}

Moving towards set goals was also, basically, a matter of being interested in the project, affirming its goals, being critical in a constructive way and striving towards the success of the project. According to one interview person, the technology to be used was not suitable and therefore it was not of interest to the activities of that organization. Furthermore, this informant said, a great number of projects within the different fields of the organization were going on, something that contributed to a tiredness of projects among both steering group members and receivers, resulting in an unwillingness to embrace the project idea and work for the attainment of the goals.

\section{Interaction patterns of the steering group}

Our observations showed that there was, at the steering group meetings, a common meeting culture in which the participants listened, gave each other room to speak, and sought to attain dialogue. The group was part of the same organization and did, therefore, recognize linguistic usage and shared a platform of values and knowledge. At an early stage, different approaches in the group emerged with some members being active and problematizing and others taking up a listening and reflecting attitude. The operative manager who had been appointed project owner was a committed member and a driving force, but had difficulties in leading the work of the group forward to decisions that could be anchored in the work activities of each steering group member.

But the group also became an arena for open and concealed exercises of power. Already at an early stage of the project period, both the project leader and the project participants experienced that they were not given sufficient support by the highest management of the county council and that separate individuals in the managerial group were openly negative to the project. This position was confirmed when one member demanded the immediate discontinuation of two sub-projects (Observation 11). This, in turn, resulted in the project 
leader choosing other ways outside of the steering group to make visible the sub-projects both internally and externally. The resistance within the County Council of Blekinge was intensified when external evaluation was set up, with the idea of making this evaluation form the basis for the decision concerning the continued existence of the project. The evaluator's assessment was, however, that the project moved in the direction of the impact- and project goals that were stated in the project plan.

An open conflict was bared when one steering group member demanded greater influence in the activities of the project at the same time as she stressed that the project had no future and that the project management therefore should not create expectations by giving information about the SGF to mass media:

\begin{abstract}
I am amazed over the project participants' insufficient knowledge of information technology. When this is the case, this has to be compensated by a steering group that masters this field. I don't think that we talk about important matters at the steering group meetings. I wanted to see a prototype and everyone was surprised that we would use meeting time for that. I have also persistently been asking for an insight into the finances and I shouldn't have to nag about that (Interview 11).
\end{abstract}

I don't think that the project is convincing and then one shouldn't be giving information about the project (Interview 11).

By spreading information within and outside of the steering group, this person tried to rouse an opinion for the discontinuation of the project. The conflict escalated, resulting in open disagreement in the steering group. Somebody felt that a person who was not "behind the project idea" ought to give up the steering group assignment and meant that the conflict that had occurred resulted in disagreements and questioning that were not constructive:

There is a lot of resistance to the project in the steering group. Sometimes it's rather subliminal, but it regularly becomes very concrete. One example is the external evaluator who suddenly contacted us. This happened because there are, within the steering group, persons who are active opponents and strongly advocate discontinuation. But it's much more difficult to handle the passive opponents because there is nothing concrete to consider. They don't want the project to succeed and not for anything to happen. By sending emails to the highest managers of the County Council and questioning the continued existence of the SGF they offer as much resistance as they can (Interview 5).

Another expression of the exercise of power was the considerable absence of group members at meetings. As early as at the constituent steering group meetings, it was observed that three of the group's members notified their absence. Someone chose to send a substitute, a pattern that was sedimented in the steering group. One steering group member was never present, but was, in contacts with the management of SGF, strongly critical to the project idea and the activities that were planned and carried out: "There is much criticism to present and furthermore I have never been able to be present. The project leader books meetings without looking in my electronic calendar. Perhaps she feels that my being present or not is of no interest" (Interview 13). This approach was discussed at each steering group meeting.

Several members felt that there was an active resistance from this steering group member, who represented the highest management of the country council, with the consequence of insecurity and the spreading of rumors. The following three quotes illustrate the opinions that these interview persons expressed:

Presence is always about personal prioritization and commitment. I attend several meetings where everybody is always present. This depends on them finding it important and believing that they will miss something if they're not there. When they are not present, it often depends on a feeling that they are not 
important to the project or what connection the project has to her/his own work activities (Interview 2).

I believe that the members find that it doesn't matter if they attend or not. I think that the steering group meetings should be remunerated. Another alternative is to include the assignment in every higher official's position. If you then don't take your responsibility in the steering group, you can formally claim that the job is not being done properly. The order must, perhaps, be obligatory for something to happen (Interview 3).

You have to take the assignment seriously. I take it as negligence. They come when they feel like it and most of the time it doesn't seem as if they feel like it. That doesn't work. The problem with the members not attending is that we don't make any decisions. We have, for example, not been able to solve technical problems in the project, something that has led to the time plan not being kept (Interview 5).

The last quote shows that the members' absence has meant that the group has not been competent to make decisions. At one point matters were driven to extremes when the project owner, during an on-going steering group meeting, over the telephone contacted the absent members who had not notified their absence, urging these to present themselves so that the group would be competent to make decisions.

\section{Analysis of empirical themes}

\section{Directing an innovation project}

The steering group's assignment to run such a complex project as SGF involves several difficulties. The project actors were politicians, civil servants, project participants and receivers; together they constituted a group with conflicting interests. During the project period the actors were confronted with both explicit and implicit power structures, which they did not understand or could not handle. To strengthen the position of SGF, most members of the steering group were managers in the highest level of the organization and, moreover, resource owners and project receivers. Several of them had earlier worked in projects or in steering groups. A fundamental problem was that the steering group, for which the departure point was goal steering, was to direct an innovation project where the results could not be defined fully in advance. As the goals of the project were unclearly formulated, thereby being subject to different interpretations, disagreement and power struggles were produced in the steering group. This complex of problems can be compared with the results of Weick and Quinn, who in their research have found that goal steering of innovative projects becomes restricted by unclear goals that easily become static and contradictory (Weick \& Quinn, 1999).

\section{Position in the hierarchy}

The position in a hierarchical structure can be related to the exercise of power and be described in terms of professional affiliation, prestige and social reputation between groups of individuals (cf. Weber, 1921/1983). The group members' power positions within the organization can also be described using Chernesky and Tirritos' four structural sources of organizational power, namely, central networks, key positions, access to resources and control of uncertainty factors (Chernesky \& Tirrito, 1987). The members who were managers on the highest hierarchical level belonged to a central network, as they had contacts with other decision-makers at the same level, for example, politicians and operative managers. The networks could be used to spread information about the project, but also to anchor the idea that the project was too costly for the County Council and should, therefore, be discontinued. 
Having a key position made it possible to affect processes so that the project would attain its set goals. But the position could also be a useful tool to render the project more difficult when it came to carrying out activities within the different organizations. Access to resources meant actively contributing to the attainment of goals. When members in the steering group who had access to this source of power by virtue of their managerial positions did not create conditions for tests in the project, the time schedule could not be kept. The fourth source of power, control of uncertainty factors, is about taking stock of environments and individuals with the purpose of setting priorities, resources that are invaluable in a steering group, but that most members in the steering group did not use to their full potential. The four structural sources for the exercise of power thus became a tool to enforce, alternatively delay or impede activities in the project.

When managers at the highest level did not give priority to members in the steering group, alternatively send substitutes, the power structure in the group was changed and resulted in reduced ability to influence, enforce and anchor the project in the respective organizations. The pattern of cancelled meetings and few participants at the meeting resulted in a transfer of the decision-making process to the level of the project management. The project leader, thus, attained a prominent power position, which, however, was complicated by her lacking the authority and resources for access to the different work organizations that were involved in the project.

\section{Power relations}

The group members' recurrent pattern of not giving priority to established meeting schedules in favor of other tasks can also be understood from the perspective of the instrumental exchange theory represented, among others, by Peter Blau, James Coleman and Rickard Emerson. The basic interplay mechanism is then explained in terms of social attraction. This means that two parties enter into an exchange relation because they both, mutually, understand that the other one has an attractive "utility" and they make the assessment that they can make an exchange without too high "costs". The condition of a person's attraction power consists of her/his control of resources. Resources, in this context, refer to relationally determined resources, which are desired by other people. An individual's action competence and resources consist, partly, of strategic resources, which determine the attraction power, and partly of resources that the individual possesses in and through her-/himself. One of the most important individual resources is insights about which utilities one possesses and about what is required for others to agree to an exchange (Coleman, 1990; Blau, 1964/1984; Emerson, 1962).

In the steering group, the exchange relation was characterized by the fact that the members with the highest positions in the County Council had strategic resources that were wanted by the project in the form of access to information about comprehensive goals of direction and priorities. This strategic resource became particularly effective in a time of cuts and financial deficit. By virtue of their positions, these actors were also expected to possess high professional knowledge to be used to promote development and innovations, that is, attractive resources of their own. At the steering group meetings this became observable when someone made her-/himself attractive by pointing to a close relation to the County Council Director or emphasized work in other contexts where this member had been strong and able to influence and change. But the members' own resources could also be expressed in the action alternative of pointing out, in an authoritative manner, the direction for SGF. In relation to the resourcestrong members, the actors in the steering group who had limited resources became more dependent upon the specific relation, something that may explain the growing irritation in the project over the fact that the resource-strong members in the steering group would not give priority to meetings or would only participate to a limited extent. The room for action for the 
actors with high accesses to strategic resources sedimented this pattern. The actors' power positions could, be said to be tied to a relation in which she/he who was most dependent on the other was at a disadvantage. The power was manifested as negotiation gains, which meant that the resource-weak party had to submit to the resource-strong party. Power is thus, when defined in terms of dependency, a community of relations and not a quality in the individual actor.

\section{Powerlessness}

As we have shown in the results section, considerable time was spent on information about the on-going work and on updating group members who had been absent at previous meetings. In some sub-projects, the activity degree was strikingly low while in others it developed according to the time schedule and the planned tests. The project leader was well aware of this and described her desperation over having too few decisions made by the steering group. Despite the support that failed to appear from the steering group the project, was, however, moving ahead and together with the project owner she made several important decisions. Action can be understood from the concept of powerlessness. Powerlessness is then defined as being in a situation where you cannot see any way out or any ability to change a situation. When the project leader started acting independently, the powerlessness was broken and the continued existence of the project was secured (cf. Mathiesen, 1978). The project leader's feeling of impotence can also be understood through the studies that Svensson et al. have carried out. These results show that a professional steering group defends a close dialogue with the project leader. If the interplay between these parties works, conditions for reflection and learning are created, and new actions are tried by engaged participants (Svensson et al., 2007).

\section{Power strategies}

The exercise of power within the steering group can also be made clear with the point of departure in Foucault's thinking. Power is this case not understood as something that the individual exercises or is exposed to. According to Foucault, power is, instead, something that exists everywhere in the relation between people and that surrounds them and comes into being and is manifested in different discourses. In the study of power, attention should, therefore, be directed to the effect on the persons exposed to the exercise of power (Foucault, 1980a). In the steering group there were three different power spheres with networks extending over the members. One was the individuals in the group that by virtue of their positions made decisions that concerned the project. The other sphere of power did not use its authority for decision-making but did not give priority to the steering group meetings. The third one was embraced by those who due to their positions in the hierarchy had limited possibility to exert an influence. The effects of the power spheres that existed in the steering group were that several of the individuals who had the greatest access to power did not take their responsibility in the steering group, resulting in this power sphere turning into a counter vector to the other two. The collected force that should have driven the project forward was, thus obstructed and the group functioned more as a reference group in spite of the fact that the group had the mandate to make necessary decisions (cf. Brulin, et. al., 2009).

\section{Resistance}

The exercise of power that existed in the steering group was also a matter of resistance and concealed power games through delaying and not executing decisions (cf. Lukes, 1986; 1979; 1977). Members of the steering group with a high capital of power could legitimise this exercise of counter-power by referring to rules and orders that had been issued at the managerial level of the County Council (cf. Mathiesen, 1978). The structure, however, put 
limits to the exercise of power that the individual steering group member could practice. The analysis of counter-power can also be referred to Foucault, who understands power as a struggle about winning or losing. Thereby, the power forms a resistance, a counter vector directed in the opposite direction of the original. The interest is not directed at those in power but at the effect that the exercise of power achieves. Mathiesen uses the concept counterpower and means that it arises when the power is disturbed (Foucault, 1980a, 1980b; Mathiesen, 1978).

When a steering group member both openly and in a concealed way fought for the discontinuation of the project this was understood, by the others in the steering group, as a serious threat to the project and as a loss of information control. As this member had access to ultimate sources of organizational power, that is, central networks, key positions, resources and control of uncertainty factors, the resistance became effective resulting in extensive discussions about the results of the project (cf. Chernesky \& Tirrito, 1987). The counterpower exercise described can also be interpreted from Foucault's view of power as relative strengths between different forces. A force never exists separately but only in relation to other forces. Power should, therefore, be interpreted as a net of tense and effective relations and not as a privilege that someone may be in possession of (Foucault, 1980a; 1980b, 1982).

\section{Conclusions}

By studying the steering group from the perspective of the acting individuals, the meaning of the actions and consequences, we have come closer to an understanding of the problems that exist in steering groups. The focus of our interest has been to try to capture, from the perspective of a specific steering group within the context of Structural Funds projects, interaction patterns and social interplay mechanisms. For a steering group to be able to exercise its assignment, four interacting conditions have been identified. Firstly, the steering group member needs to have a positive attitude to the project idea and the indicated goals. Knowledge of the assignment is another condition as is the condition that the steering group member should have a position with the authority to make and carry out decisions that are strategic for the project. Time must, finally, be allocated for active work and participation in the meetings.

The interaction patterns that emerged in the studied steering group rested on two foundations. The first one was that social relations within the steering group created power which became manifest in different ways. In their social relations, the actors in the study marked their power positions. These had their basis in each steering group member thinking and acting in a context at the same time as possibilities and limitations were determined by the actual context. This meant that the actor in her-/himself was a product of the power relations. Seen from a relational perspective, power within the steering group was not only created by those high up in the hierarchy. It was rather so that power was created in the different actors' mutual dependence on each other's activities (cf. Emerson, 1962).

When different interests met, the power relation was used to create conflicts, and the state of dependence that existed between the members in the steering group who had high access to strategic resources and those who had little access meant that a power-asymmetrical social relation was created. This was characterized by one party being able to take greater advantage of the exchange relation than the other party, something that became clear when meetings were not given priority in favor of more important meetings, when the members left the meeting after a short while or were not sufficiently prepared for the questions that were to be dealt with at the steering group meetings. This exercise of power can also be seen as a resistance strategy; the resource-strong actors used their advantage of power for the shaping 
of rules that benefited these actors' interest at the same time as it would be a disadvantage to those with less access to organizational power in the form of strategic resources.

The other foundation was that the exercise of power affected the action outcome, that is, the result of the actions and consequences for future actions. A social action is built up by the actor needing to have competence and resources for action. Furthermore, there has to be an intention and a meaning with the action, an action environment and a consideration of the consequences of the action. Together these factors enable and restrict each actor's actions.

The relation between intentions and the factual consequences of the steering group's actions can be analyzed from the action outcome. If the group had developed the capacity to interact and created stable social relations, creativity as well as work achievements would, probably, have been attained. Instead, actions like being absent from meetings, delaying decisions and spreading negative information about the status of the project externally contributed to action outcomes that did not carry the project towards the established goals but, rather, towards skepticism from the surroundings and threats of discontinuation. During the last year of the project, the work of the steering group was, however, done according to a more continuous structure with clear agendas for the accounting of the project status and offensive planning for how the project would be implemented in the different activities of the county council, something which resulted in the project concluding with goal attainment in various areas.

All in all, the empirical data in our study indicate that the interaction patterns that could be observed in the steering group affected the action outcome and that this did not always turn out the way the actor had thought it would, with both intended and unintended consequences. Knowledge of the two foundations, that is, social relations and the action outcome in relation to the exercise of power, leads to thoughts on change. An important part in this is to recreate structural relations. Another is to achieve change with the point of departure in the individual. The group members' consciousness and knowledge of the exercise of power and its action outcome then become central. If a steering group is to live up to the expectations that exist from project management and project participants, the social relation also needs to provide conditions for trust and thereby the possibility to attain common goals in the steering group work.

In this article we have problematized the steering group's assignment to direct an innovation project that extends over several years. The result contributes new knowledge in the research area and should be possible to transfer to other steering groups but also to all group meetings in the working life that build on interaction, the creation of social relations and interplay.

The study also raises the research question of how the regulated work that is carried out in a steering group could be reorganized to create conditions for relations building on competence, that is, a joint and reciprocal structure of competence. The point of departure would, thus, be that knowledge is brought into being and exists when individuals interact with each other. 


\section{Literature and Sources}

Albinsson, G., Arnesson K. (2010). How Critical Can You Be as an On-going Evaluator? International Journal of Action Research. 6 (2-3): 256-287.

Antvik, S., Sjöholm, H. (2006). Project - Management and Methods .Stockholm: SIS förlag.

Blau, Peter. (1964/1984). The Dynamics of Bureaucracy. A Study of Interpersonal Relations in Two Government Agencies. $2^{\text {nd }}$ Edition. Chicago: University of Chicago Press.

Brulin, G., Svensson, L. (2012). Managing Sustainable Development Programmes. A Learning Approach to Change. Farnham: Gower Publishing Limited.

Brulin, G., Svensson, L. (2011). Att äga, styra och utvärdera stora projekt. [Owning, Managing and Evaluating Large Projects]. Lund: Studentlitteratur.

Brulin, G., Sjöberg, K., Svensson, L. (2009). Gemensam kunskapsbildning för regional tillväxt. Arbetsmarknad och arbetsliv I [Common knowledge formation for regional growth. Labour market and working life I]. Karlstad: Universitetstryckeriet.

Bruzelius, L., Skärvad, P-H. (2004). Integrerad organisationslära. [Integrated learning]. Lund: Studentlitteratur.

Bryman, A. (2010). Social Research Methods. Oxford: OUP.

Chernesky, R. \& Tirrito, T. 1987. Sources of Organizational Power for Women in the Health Care Field. New York: Haworth Press.

Cohen, L., Manion, L., Morrison, K. (2007). Research Methods in Education. London and New York: Routledge.

Coleman, J, S. (1990). Foundations of Social Theory. Cambridge/Massachusetts: University of Harvard Press.

Dey, I. (1993). Qualitative Data Analysis. A User-Friendly Guide for Social Scientists. London: Routledge.

Denscombe, M. (2007). The Good Research Guide. Milton Keynes: Open University Press.

Ely, $M$ et al., (1997). Doing Qualitative Research. Circles within Circles. London: Routledge Falmer.

Emerson, R. (1962). "Power-dependence Relations”. American Sociological Review, (27): 3141.

Fielding, N., Fielding, Jane. (1986). Linking Data. London: Sage Publications Ltd.

Foucault, M. (1982). The Subject and Power. Critical Inquiry, (8): 777-795.

Foucault, M. (1980a). Power/Knowledge. New York: Pantheon.

Foucault, M. (1980b). Power/Knowledge. Selected Interviews and Other Writings 1972-1977. Brighton: Harvester P. Inc.

Landstinget Blekinge[the County Council of Blekinge] (2008) . Projektplan [Project plan]. Syster Gudruns fullskalelaboratorium i Blekinge för It $i$ vård och omsorg [Nurse Gudrun's Full-Scale Laboratory in Blekinge for IT in Nursing and Caring].

Lukes, S. (Eds.). (1986). Power. Oxford: Basil Blackwell.

Lukes, S. (1979). On the Reality of Power. In S. C. Brown (Eds.). Philosophical Disputes in the Social Sciences. Hassocks: Harvester.

Lukes, S. (1977). Power and Structure. Essays in Social Theory. London: Mac Millan Inc.

Macheridis, N. (Red.), (2009). Projektaspekter. Kunskapsområden för ledning och styrning av projekt. [Project aspects. Areas of knowledge for command and control of projects]. Lund: Studentlitteratur.

Macheridis, N. (Red.), (2005). Ekonomiska perspektiv på projekt. [Economic perspectives on rojects]. Lund: Studentlitteratur.

Mathiesen, T, (1978). Makt och motmakt. [Power and resistance]. Göteborg: Bokförlaget Korpen. 
Patton, M. Q. (2002). Qualitative Research \& Evaluation Methods. London: Sagos Publications.

Svenning, C. (1993) $3^{\text {rd }}$ edition. Method 102 - Social Science Methods and Method Development. Eslöv: Lorentz Förlag.

Svensson, L., Aronsson, G., Randle, H., Eklund, J. (2007). Hållbart Arbetsliv. Projekt som gästspel eller strategi $i$ hållbar utveckling. [Sustainable working life. Projects as guest performance or strategy of sustainable development]. Malmö: Glerups.

Swedish Agency for Economic and Regional Growth. (2008). Projektdirektiv för projektet Syster Gudruns fullskalelaboratorium i Blekinge för It i vård och omsorg. [The Directive of the Project Nurse Gudrun's Full-Scale Laboratory in Blekinge for IT in Nursing and Caring].

Tonnquist, B. (2008). Projektledning. [Project management]. Stockholm: Bonniers förlag.

Trondman, Mats.(1997). Cultural Studies - den personliga bekännelsens project [Cultural Studies - project of the personal confession]. Zenit. (135-136): 69-88.

Weber, M. (1921/1983). Economy and Society. An Outline of Interpretive Sociology. Columbia and Princeton: University Presses of California.

Weick, Karl., Quinn, Robert. (1999). Organizational Change and Development. Annual Reviews Psychology. (50): 361-386. 